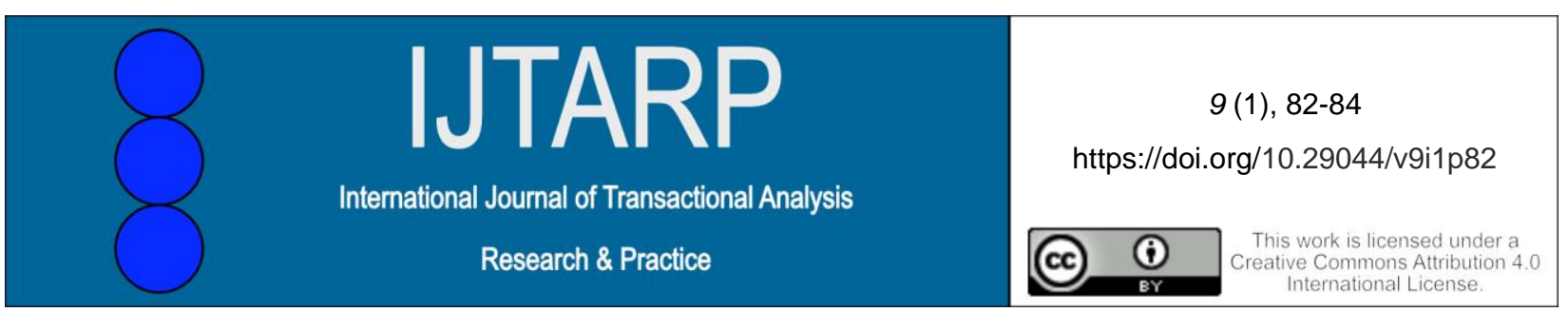

\title{
Book Review: This is me! Becoming who you are using Transactional Analysis by Lieuwe Koopmans
}

\author{
(C) 2018 Cathy McQuaid
}

Lieuwe Koopmans (2017) This is me! Becoming who you are using Transactional Analysis Hertford: Sherwood Publishing - 118 pages pbk/ebook

Reviewed by Cathy McQuaid

One of the first things that struck me about this book was the bright red cover, very eye catching, and second was the size of the book, almost a pocket book in terms of being 120 pages in length. I had a sense of it being easily accessible and from the engaging stories knew I was in for a treat.

I also noted that the book comes with endorsements from within the TA community: a Foreword by Julie Hay TSTA (Organisational, Psychotherapy, Educational) and back cover endorsements by Trudi Newton TSTA (Educational), Sandra Wilson TSTA (Organisational) and Graeme Summers CTA (Psychotherapy).

This book is for anyone who wants to know more about themselves and why they may be stopping themselves from reaching their own potential. It is excellent for clients, in any field of application. Koopmans uses himself throughout the book, via his own personal stories or through his work with his clients. The book is well written, easy to read and the numerous examples throughout bring the theory alive. Throughout the reader is presented with a variety of questions to help them identify their own processes and what may be hindering them reaching their potential.

The book is structured like a play, with acts, chapters and numerous players, including the reader, and with a Prologue, First Act, Second Act, etc. Each Act has chapters and some information for the reader to consider and questions are posed to the reader inviting them to discover more about their history, reasons for creating their own mask, for their life choices, discovering relationship patterns and what the reader can do to turn their life around. There are 'Sources of Inspiration' for those who want to learn more, a brief introduction to the history of TA with information on training in TA, a useful glossary of TA concepts, and 'proper' references back to originators for the TA and non-TA concepts mentioned in the book.

The Prologue begins with three brief cameos, Carl, Caroline and Christine, illustrating how each tell something of their life story, something that has previously been hidden from others, and the response that they get from the 'other'.

Koopmans continues that we all have masks to cover up who we truly are perhaps because we have a notion that somehow, we are not good enough or acceptable. Numerous TV programmes let us know that with a makeover or 'quick fix' we can live happily ever after and so this adds pressure on some people to let others know how well they are doing, but it also means that others may gloat over someone else's misfortune, hence the popularity of certain clips on YouTube or TV programmes like 'Jeremy Kyle' that expose and open to ridicule people who are vulnerable and yet who also want their 10 minutes of fame. There is permission to be voyeurs of the self-destruction of others, after all "they volunteered to be on the programme," whilst at the same time those watching can feel smug that although their life isn't perfect at least it's not as bad as those on the TV.

We are introduced to Jung's differentiation between a 'perfect life' and a 'full life'. In the perfect life some parts of us must be denied, anything other than perfection must be covered up whereas a full life allows for everything to have meaning. We are invited by Koopmans to use the book to help us get a full life, discovering previously hidden aspects of our personal history and consider how this may impact on our current behaviour.

'The First Act: The unspoilt life' - firstly invites the reader to consider what motivates them and asks 'What do you want to achieve: professionally? In your private life: with your family or friends? In your leisure time, hobbies or sports? A further question 'Have you 
set any goals for yourself or do you harbour any secret desires?' is also posed. There is then an introduction to 'physis' and the six drives that encourage us to grow. A case example is given of 'Annette' who is invited to draw an outline of an aquarium and to draw rocks in it that illustrate the main values in her life, she then adds in other values (rocks) of different sizes that denote their importance to her and her life. The reader is then invited to create their own aquarium and to consider whether it is a true reflection on their current life.

The next chapter looks initially at bonding and then child development, each stage is illustrated with examples from early childhood and from later stages in life. The questions for the reader invite them to consider what stage of development they may be at in work, in their private life and whether they may be stuck in more or more stages.

'Second Act: Masks and Make-up: the camouflage of life' introduces the reader in Chapter 3 to the structural model of ego states. Each ego state is explained and illustrated with examples which are easy to read and thought provoking. Again, questions are posed throughout inviting the reader to consider their own ego states.

Chapter 4 continues with an introduction to the functional model of ego states and how we may communicate with others from the different ego states. This leads into an introduction to transactions and transaction patterns. Numerous questions are posed inviting the reader to really 'play with' the theory and observe how they may look and behave differently depending upon what and how they may say something.

Chapter 5 takes a good look at the Adult ego state, offers the reader a magnifying glass look at the Adult which reveals five behaviours: Structuring, Nurturing, Accounting, Cooperative and Spontaneous. The reader is invited to reflect on a previous example and decide which of these behaviours they were applying. There is a short interlude with an introduction to the Unconscious Incompetence model of learning; this is a great addition and gentle reminder that when learning something new there is a potential for awkwardness and possible shame. The example offered is, when learning to drive a car, how we may go from not knowing anything about driving a car, to the first driving lessons and sense of being clumsy, to being able to drive competently but it still needing $100 \%$ effort, to finally driving automatically.

'Third Act: Life Script' introduces the reader in Chapter 6 to the concept of Life Script and to the Script circle, something I had not heard of before. The circle consists of a number of recurrent steps: Experience, Interpretation, Conclusion, Conviction, Behaviour,
Reaction, Decision, Behavioural Pattern, Reaction, Pay-off and back to Interpretation. The reader is invited to create their own script circle based on an experience they have had or an important decision they have made regarding who they want to be in life. The reader is then asked to review their experiences and whether alternative decisions were available, with the aim of helping the reader to gain a different perspective. Loyalty is discussed and examples are given to illustrate how loyalty is the bedrock of script.

Chapter 7 brings in the various components of Script. Koopmans describes the messages children receive as akin to road signs that we see daily. Permissions are introduced as are Injunctions. The injunctions are each illustrated with an example and the reader is encouraged to consider that injunctions they may have. This is followed by Drivers, again each is explained in layman's terms and an example given to bring the theory alive and the reader asked to identify their own driver behaviour. There is then a link back to one of the cameos mentioned in the prologue where Carl is able to identify his injunctions, drivers and permissions.

'Fourth Act: How the Script is developed' leads in Chapter 8 with the significance of strokes, the types of strokes and how we may deal with strokes in life, the stroke economy and then moves into time structuring. Each stage of time structuring is explained and an example given to bring the theory to life. The chapter ends with questions for the reader to consider in terms of their own time structuring and level and types of strokes.

Chapter 9 focusses on the significance of emotions, the link between emotions and script and rackets. What is often regarded as the core emotions e.g. fear, anger, sadness and happiness are explained and the reader invited to consider when they last experienced that particular emotion, to identify the cause, their need at that time, what they did and what happened. Racket feelings are then explored, the reasons for their origins and how to work with rackets. This chapter ends with a brief update on Caroline, introduced in the prologue, and her time structuring, strokes and emotional patterns.

Chapter 10 is about the possibility of change or "how to remove the make-up'. Autonomy is explored along with awareness, intimacy, spontaneity and integrity and the reader is invited to recall a time when they have been autonomous. The chapter moves on to discuss redecisions and how a redecision is possible, the case example of Gus brings the theory and process of redecisions to life. As usual the reader is invited to create an action plan for their own redecision process. The chapter finishes with an exploration of working with drivers and injunctions and contains 
some recommendations for dealing with each of the drivers.

'Fifth Act: Getting the show on the road' starts with Chapter 11 Windows on the world (the OK Corral), and moves to Chapter 12 Transference, Chapter 13 Games, the drama triangle and the winner's triangle and Chapter 14 Symbiosis. Each concept is explained and illustrated with examples. Although the concepts increase in complexity they are explained in layperson's terms and again the examples are easy to follow and understand. Throughout the reader is encouraged to identify their own patterns, transferences, games and drama triangle positions. Interestingly Koopmans also introduces the role of the Bystander, a role that I think is often missed when considering what role(s) we may play in a game process. The chapter concludes with an update in Christine, introduced in the prologue.

'Epilogue: About the free choice for development' begins with Chapter 15 connecting to vital energy (physis) and the courage to live (thymos) and the reader is asked whether there is anything that is preventing them from doing what they really would like to do. They are then encouraged to 'un-cover' their own answers. The chapter ends with the words 'tick, tick tick, tick' meaning the clock of life is ticking away, don't wait until it's too late! Koopmans also suggests '... take off our masks, take off our make-up and get up on the stage, stand in the spotlights and say:

'THIS IS ME!' 